\title{
Dynamic Capabilities and SMES Performance: The Mediating Effect of Innovation (Study of SMES in Indonesia)
}

\author{
$1^{\text {st }}$ Titi Kurnia Fitriati \\ State University of Jakarta Indonesia \\ Rawamangun Muka Street \\ RT,11/RW.14 Sub District Pulo Gadung \\ East Jakarta 13220, Indonesia \\ titikurnia_im17s3@mahasiswa.unj.ac.id
}

\author{
$2^{\text {nd }}$ Dedi Purwana \\ State University of Jakarta Indonesia \\ Rawamangun Muka Street \\ RT,11/RW.14 Sub District Pulo Gadung \\ East Jakarta 13220, Indonesia
}

\author{
$3^{\text {rd }}$ Agung Dharmawan Buchdadi \\ State University of Jakarta Indonesia \\ Rawamangun Muka Street \\ RT,11/RW.14 Sub District Pulo Gadung \\ East Jakarta 13220, Indonesia
}

\begin{abstract}
The purpose of this study is to analyze the relationship between dynamic capabilities and SME performance, dynamic capabilities with innovation, and innovation with SME performance. In addition to analyzing whether innovation can mediate the relationship of dynamic capabilities with SME performance. The research data to be used is SME data in Indonesia with primary data through questionnaires and secondary data published by the Government of Indonesia. The research sample is 350 SMEs in Indonesia.The method used is the causality method to determine the relationship between variables and to determine the direct effects and indirect effects of dynamic capabilities on the performance of SMEs, data analysis techniques using SEM. The results of this study indicate that (1) there is a positive relationship between dynamic capabilities and SMEs performance, (2) there is a positive relationship between dynamic capabilities and innovation (3) there is a positive relationship between innovation and SMEs performance (4) there is a positive relationship between dynamic capabilities and SMEs performance through innovation as mediation.
\end{abstract}

Keywords-Dynamic, SMES, innovation

\section{INTRODUCTION}

In the business world, including small and medium businesses (SMEs) today there is rapid competition in line with the growth of the national economy. This condition is due to the markets faced by developing companies and companies must be able to make a difference by innovating. Companies must be able to create products or services according to the needs of consumers who are increasingly smart in choosing products and services. SMEs in Indonesia plays a very important role as economic support. SMEs are the main driver of the economy with the main function of SMEs being able to provide employment for millions of people absorbed in the formal and informal sectors. SMEs have contributed to the formation of the Gross Domestic Product (GDP) and the SMEs sector as a source of foreign exchange through the export of various types of products from SMEs.

Finance Minister Sri Mulyani Indrawati (Kompas.com, 31/10/2018), said that support for MSME is an important element for the Indonesian economy, because MSME is able to absorb $96 \%$ of the workforce and contribute $60 \%$ to GDP (Gross Domestic Product) (https://ekonomi.kompas.com/read/2018/10/31/2041003 26/sri-mulyani--umkm-serap-96-persen-tenaga-kerja). Referring to the opinion, it is important to study by conducting research related to dynamic capabilities, innovation and performance of SMEs, in this research the priority is in the food and beverage industry as the main need for human life.

In management the main strategy is the ability to compete with dynamic capabilities (Teece, Pisano, \& Shuen, 1997). The concept of resource-based view is key in dynamic capability research (Wennerfelt, 1984; Barney, 1991, Peteraf .1993, Amir \& Shoemaker 1993; (Cabral, 2010)) and (Hernández, \& Bautista, 2017).

The company's human resources are believed to be an important source of sustainable competitive advantage (Muhammad, Abro, Memon, Irfanullah, \& Arshdi, 2011). This is especially true for companies operating in complex and dynamic competitive environments where the ability to quickly acquire and assimilate new markets and technological capabilities is key to maintaining an advantage over competitors according to Barney's opinion (Cabral, 2010). Dynamic capabilities are the company's ability to integrate, build and reconfigure internal and external competencies to deal with rapidly changing environments (Teece et al., 1997) ; (Teece, 2014); (Ackdilli Gaye and Dogan, 2013) Zollo and Winter (2002), "A dynamic capability is a learned and stable pattern of collective activity through which the organization systematically generates and modifies its operating routines in pursuit of improved effectiveness ". Dynamic capabilities reflect an organization's ability to achieve new forms of innovative competitive advantage as a result of given path dependencies and market positions according to Helfat (2007) (Ramón, Lorenzo, Teresa, Rubio, \& Garcés, 2018).

Quality human resources is an important tool for small and medium enterprises (SMEs) who seek to utilize their human capital and improve their entrepreneurial performance. Entrepreneurial performance refers to the ability to innovate, accept the risks of identifying and 
taking advantage of entrepreneurial opportunities. Small and medium businesses (SMEs) in Indonesia really need a comprehensive and integrated approach in an effort to improve business development and maintain customer loyalty so as to improve organizational performance better. In an effort to improve organizational performance. The problem in this research is how dynamic capabilities improve innovation and performance of small and medium enterprises (SMEs). In the global market competition, companies are required to continue to develop innovation, by taking into account the structure of the industry by examining from an internal perspective as carefully as available resources by combining to obtain competitive advantage (Prahalal and Hamel, 1997). A company that is able to provide positive, timely, fast and responsive responses with flexible product innovations and integrated management capabilities with effective coordination and appropriately locate internal and external competencies is the winner (Strønen, Hoholm, Kværner, \& Støme, 2017).

Company performance is a result that is made by management continuously which is the result of the decisions of many individuals (Helfert, 2000) revealed that organizational performance is something that illustrates the extent to which a group has carried out all the main activities so as to achieve the vision and mission of the institution.

Company performance as a product success and market development, where company performance can be measured through sales growth and market share (Lee \& Tsai, 2005) ; (Pelham \& Wilson, 1996). Baker and Sinkula's research (1999) states that market orientation and individual learning orientation influence organizational performance which can be measured by indicators of market share growth, the success of new products and overall performance. Good company performance is expressed in three main quantities, namely sales value as indicated by the value of money or unit profits, sales growth as indicated by an increase in product sales and market share as indicated by-product contribution in controlling the product market compared to competitors who ultimately lead to profits company (Ferdinand, 2002: 3); (Mohammad, Massie, Tumewu, \& Program, 2019).

The company has done a lot of research performance (Lin, 2012); (Suliyanto \& Rahab, 2012) ; (Ozmen \& Deniz Eris, 2012) ; Cheema, 2015) ; Zafar et al., 2016)) stated that market orientation has a positive and significant effect on company performance. Different opinions from the results of Gholami and Birjandi's research (2016) that market orientation has no influence on company performance. Company performance can be measured through sales growth, profitability and market share (Lin, 2012) ; (Suliyanto \& Rahab, 2012). In contrast to Gholami and Birjandi (2016) measurement of company performance is measured through product performance and customer performance.
Innovation is the idea of openness to new ideas as aspects of corporate culture (Hurley, 2012); (Alegre, Mesa, \& Strange, 2005) Rogers (1983; 425) defines innovation as an idea, idea, practice or object/object that is realized and accepted as something new by a person or group to be adopted. (Robbins, 2005) defines innovation as a new idea that is applied to initiate or improve a product or process and service.

According to this aspect of performance is very important to strengthen financial performance and survival, especially for small companies operating in highly competitive high-tech environments, clarified by Fernandez and Alegre (Carvalho \& Sugano, 2017); ( Mesa \& Vidal, 2013). Dynamic capabilities and innovation are strategies in improving the performance of SMEs in Indonesia.

\section{LITERATURE REVIEW}

\section{A. Dynamic Capabilities.}

Dynamic capabilities are the company's ability to integrate, build and reconfigure internal and external competencies to deal with rapidly changing environments (Teece et al., 1997); Zollo and Winter (2002), "A dynamic capability is a learned and stable pattern of collective activity through which the organization systematically generates and modifies its operating routines in pursuit of improved effectiveness ". Dynamic capabilities reflect an organization's ability to achieve new forms of innovative competitive advantage as a result of given path dependencies and market positions according to Helfat, 2007 (Ramón et al., 2018).

Teece's view of dynamic capabilities is about how the ability of company or organization managers in integrating, building and configuring corporate or organizational competencies both from internal sources and from external sources to be able to adapt to rapid environmental changes so as to make internal competencies and external as a source of sustainable competitive advantage. Dynamic capabilities have unique and different characteristics that give rise to its own history for the company because the company has special characteristics that are able to distinguish the company from similar companies, the uniqueness or uniqueness in a company becomes its own attraction (Teece et al., 1997).

Barney (1991) states that "dynamic capabilities are processes embedded infirm, assuming an organization and empirical lens, rather than an economic and formal modeling one". Dynamic capabilities are processes that are embedded in the company meaning that these values are already in the company in the form of internal competence( Khaliq \& Saeed, 2015) (Khaliq \& Saeed, 2015). According to Peteraf (1993) to measure dynamic capabilities is to measure the capabilities or capabilities that are influenced by dynamic market mechanisms and their evolution, "the examine of dynamic capabilities, how those capabilities are influenced by market dynamism and their evolution over time" (Alves, et al, 2017). 
'Dynamic capabilities are the firms' processes that use resource-specifically the process to integrate, reconfigure, gain and release resources to match and even create market change. Dynamic capabilities thus are the organizational and strategic routines by which firm achieve new resource configuration as market emerge collide. Split. Evolve and die".

Dynamic capabilities are processes of companies or organizations that use specific resources to match existing market changes with the aim of adjusting to dynamic changes that occur in the market, dynamic capabilities are also a configuration of resources that are in line with product life cycle namely developed markets, impacting , divides, develops and eventually dies / disappears (Cyfert \& Krzakiewicz, 2016); (Eisenhardt and Martin, 2000; (Cheema, 2015); Khaliq \& Zafar Saeed, 2015)

According to Eisenhardt and Martin (2000) states "dynamic capabilities consistency and organizational processes such as product development, alliancing and statistical decision making that create value for firms within dynamic markets by manipulating resources into new value-creating strategies". Dynamic capability is a special strategy that is able to make strategic conclusions that create new value for companies in dynamic markets by manipulating or changing existing resources to be able to create new strategic values (Khaliq \& Saeed, 2015).

"Dynamic capabilities are the antecedent of organizational and strategic routines by which managers after the resource base - acquire and shed resources, integrate them together, and recombine them to generate new value-creating strategies" meaning that dynamic capabilities are the overall organization or company and strategy routines where managers are able to change these resources together and combine well to create a new strategic value according to Grant (1996) and Pisano (1994) (Teece et al., 1997).

According to Henderson and Cockburn (1994) states "dynamic capabilities are the drivers behind the creation, evolution, and recombination of other resources into new sources of competitive advantage". Dynamic capabilities as the root of creating evolution and recombination of resources to become new sources for competitiveness (Teece et al., 1997).

Dynamic capabilities are part of the process of an organization or company in which companies gain knowledge of resources and then these resources are integrated into new applications from available resources according to Kogut and Zander (1992). "Dynamic capabilities are the organizational processes by which firms synthesize and acquire knowledge resources, and generate new applications from these resources" (Smith \& Prieto, 2008).

"The concept of dynamic capabilities recognizes that especially companies operating in changing environments need to be able to develop dynamic view perspectives on the resources and competences in the order to create competitive advantage is developed" (Clark, 1994). Dynamic capabilities are seen from the effect of environmental change on companies that need to improve perspective from a dynamic view of existing resources and competencies to create competitiveness ( Khaliq \& Saeed, 2015).

Dynamic capabilities are more focused on reconfiguring company resources, the process is carried out by company managers who copy, transfer and recombine resources especially those based on knowledge according to Hansen (1999). "Dynamic capabilities focus on reconfiguration of resources within firms, transfer processes including routines for reflection and broking are used by managers to copy, transfer, and recombine resources, especially knowledge-based one, within the firm" (Smith \& Prieto, 2008).

According to Helfat and Peteraf (2003) dynamic capability is an approach to understanding a company's business based on the basic theory of resources that enables unique company capabilities to develop. "Dynamic capabilities are the approaches to understand business firm builds upon the basic assumptions of resource-based theory through its assertions that these unique firm capabilities develop over time" (Cheema, 2015) .

Jiao (2013) argues "dynamic capabilities are the development of management capabilities difficult to imitate the combination of organizational functional, technological and technological skills to change existing operational mechanisms in order to meet new customer needs and finally to improve performance". Dynamic capabilities are a form of management capability that is difficult to organizationally functional imitation and technological capability to change operational mechanisms to find new customer needs and the ultimate goal is to improve performance (Arief, \& Propheto, 2015)

"Dynamic capabilities are the entrepreneurial ability to adapt to rapidly changing environments". Entrepreneurial orientation is to have an innovative character, proactive and risk challenger, dynamic capabilities can be categorized into entrepreneurial abilities that are able to adapt to dynamic market changes (Teece et al., 1997).

In the current era of globalization with rapid dynamic changes, company leaders must be able to make the right decisions and be quick to adjust to the environment in the current era of disruption.

Disruption is very influential in the dynamics of a dynamic environment Disruption is influential in marketing strategies, especially small and medium-sized businesses. The effects of disruption are online business. In this era the term VUCA emerged, namely volatility (easy to disappear), high uncertainty, complexity and ambiguity, which indicates the dynamics and turbulence of the environment (Gupta, \& Sahay, 2017) .

The company's business model has the ability to create and deliver value to customers with the right mechanism. The business model shows the flow of costs, income and profits and the success of a business depends on the design of the business model and its implementation (Teece, 2018). 
Dynamic capabilities in this business model are companies having the ability to sense and seize new opportunities and reconfigure resources and capabilities and opportunities that are detected and environmental changes that can create and maintain competitiveness. In accordance with the opinion of Breznik and Hisrich. 2014 (Breznik \& Hisrich, 2014).

The design of the model depends on the capability of the company in terms of the capability of accuracy, implementation and transformation of the business model as the output of dynamic capabilities at a higher stage. The dynamic capability has become an organizational routine and managerial expertise and is the company's ability to integrate, build and reconfigure internal competencies that are in accordance with current environmental conditions with a changing business environment. The strength of a company's dynamic capabilities is key in its ability to sustain long-term profits including redesigning or adjusting business models (Teece, 2018).

Dynamic capability is something broad from dynamic resources, processes and capabilities in which a company must continuously build, adapt and reconfigure internal and external competencies to adapt to the development of the business environment. Dynamic capability functions as the company's capability for its partners. Development and coordination of company resources and corporate partners to make changes in the market and business environment. The strength of the company's dynamic capabilities determines the speed and level of ability of the company's resources in adjusting its business model according to the needs and aspirations of customers, this can be achieved by observing opportunities periodically and changing aspects and culture of the company to be more proactive towards new threats and opportunities along with business development/business (Teece, 2018).

Dynamic capability according to Teece (2018) in the business model consists of three components, namely:

- Sensing, namely identifying opportunities by always observing the environment and looking for opportunities that arise within or outside the company's boundaries.

- Seizing is when there is an opportunity then its potential and value are captured to be learned by choosing the right technology or better understanding the target customers.

- Transforming / Reconfiguring is when opportunities are perceived and captured then the company reconfigures resources to adjust changes and opportunities in the corporate environment.

Dynamic capability according to (Pandit et al., 2017) consists of: (1) sensing capability, that is finding, understanding and teaching opportunities or overcoming threats, (2) learning capability, namely restructuring existing functional competencies, creating new knowledge, (3 ) integrating capability that is combining individual knowledge and embedding it in operational capabilities through merging sense-making,
Configuration, which is facilitating reconfiguration through assigning and organizing resources and assignments for new operational capabilities (Pandit et al., 2017) ; (Teece, 2018). From the point of view, understanding and definition, dynamic capabilities of companies or organizations have the ability to manage dynamic capabilities in order to be able to survive and compete in markets that have rapid dynamic change. Dynamic capabilities are a form of knowledge that is able to create value for companies both with the results of innovation and the transformation of inputs into outputs in order to obtain a sustainable competitive advantage.

\section{B. Innovation}

The concept of innovation in research before 2000 and using the term innovation orientation after 2000 (Jabeen, Alekam, Aldaoud, Mat, Zureigat, Nahl, Junaidi, 2013) in accordance with the opinion of Eris and Ozmen (2012), innovation challenging activities and the unpredictability of existing and updated version orientations, innovation is the development of current products and production processes, as well as radical innovations that basically the development or implementation of new ideas and new technologies.

Innovation is the idea of openness to new ideas as aspects of corporate culture (Hurley and Hult 1998: 44). Rogers $(1983 ; 425)$ defines innovation is an idea, practice or object is recognized and accepted as a new thing by any person or group to be adopted. This means that innovation is an idea, ideas, practices or objects that are realized and accepted as something new by a person or group to be adopted. (Robbins, 2005) defines innovation as a new idea applied to initiate or improve a product or process and services. This means that innovation as a new idea is applied to initiate or improve a product or process and service.

Research by Lee and Tsai (2005); (Muhammad et al., 2011) ; and (Suliyanto \& Rahab, 2012) suggested that innovation influences company performance. Innovation can be measured by how often companies introduce innovations in processes, products, marketing and management (Serna, 2012). So innovation is an idea, an idea that is realized and accepted by a person or group for improvement in products, processes, marketing and management.

Product innovation: the introduction of products or services that are actually newly introduced to consumers as a renewal of existing products or have gone through significant improvements related to the characteristics or intended use of the product. Process innovation: the application of production or delivery methods that are completely new or have gone through significant improvements. Marketing innovation: the application of new marketing methods or a significant increase in the product packaging or design, product placement, product promotion and prices with the aim of increasing sales, meeting consumer needs, opening new markets, placing company products in the market. 
Management/organization innovation: the application of new organizational methods to business practices, workplace organization, company external relations. From the opinions above, it is synthesized that innovation is the process and result of developing the use/mobilization of knowledge, skills and experience to create or improve new products, processes and systems that can provide significant value.

\subsection{SMEs Performance}

Business performance is a result made by management continuously (Helfert, 2000). The intended outcome is the result of the decisions of many individuals, Keban (2004) reveals that organizational performance is something that illustrates to what extent a group has carried out all activities principal so that it can achieve the vision and mission of the institution.

Company performance is a factor that is often used to measure the impact of the strategy set by the company as a product market achievement where each company has an interest in knowing the market performance of its products. Market performance of the product, measured by an increase in sales, increased market growth and market share according to Ferdinand, 2002 (Fischer, 2013).

Pelham and Wilson (1996: 31) define company performance as product success and market development, where company performance can be measured through sales growth and market share. Baker and Sinkula's research states that entrepreneurial orientation individually influences organizational performance which can be measured by indicators of market share growth, the success of new products and overall performance. Good company performance is expressed in three main quantities, namely sales value as indicated by the value of money or unit profits, sales growth as indicated by an increase in product sales and market share as indicated byproduct contribution in controlling the product market compared to competitors who ultimately lead to profits the company in accordance with the opinion of Ferdinand, 2002 (Fischer, 2013).

Company performance or business performance or organizational performance is the result of activities carried out by the organization within a certain period (Hult, Hurley, \& Knight, 2004). Company performance has been widely researched, Baker and Sinkula (1999); Lin et al., (2008); (Suliyanto \& Rahab, 2012) shows that market orientation has a positive and significant effect on company performance. Eris and Ozmen (2012); Zafar et al., (2016) stated the same thing that market orientation had a positive and significant effect on company performance. Different opinions from the results of Gholami and Birjandi's research (2016) that market orientation has no influence on company performance. Company performance can be measured through sales growth, profitability and market share (Li et al., 2008); (Suliyanto \& Rahab, 2012). In contrast to Gholami and Birjandi (2016) measurement of company performance is measured through product performance and customer performance.

The performance of SMEs is basically the same as company performance because SMEs are a type of small and medium business. The performance of SMEs in Indonesia is seen from the aspects of: (1) added value, (2) business units, labor and productivity, (3) export value.

Added value is the performance of the Indonesian economy created by SMEs this year when compared to the previous year. Business units and labor are total business units in Indonesia and labor is the total workforce available in business units or SMEs, productivity or results of a business. SME exports are the products of SMEs exported abroad which have increased from year to year. From some of the opinions above, it can be synthesized that the performance of the company / SME is a result made by the management/company continuously and is the result of the decision of many individuals to achieve the company's goals both small and medium-sized businesses.

\section{THEORETICAL FRAMEWORK AND HYPOTHESIS}

The theoretical framework in this study is to examine and examine empirical information about the direct and indirect effects of these variables: innovation as a mediation of dynamic capabilities, knowledge management and entrepreneurial orientation variables on SME performance. Small and medium-sized businesses have so far not developed innovation to create superior value for customers and can improve company performance.

Theories used in explaining the effect of dynamic capabilities on innovation are according to Teece et al (1997), Zollo and Winter (2002), dynamic capabilities are companies having the ability to integrate, build and reconfigure internal and external competencies to deal with changing environments with fast (Teece et al., 1997) so that companies have a competitive advantage in developing markets (Helfat, 2007).

Teece's view of dynamic capabilities is about how the ability of company or organization managers in integrating, building and configuring corporate or organizational competencies both from internal sources and from external sources to be able to adapt to rapid environmental changes so as to make internal competencies and external as a source of sustainable competitive advantage. Dynamic capabilities have unique and different characteristics that give rise to its own history for the company because the company has special characteristics that are able to distinguish the company from similar companies, the uniqueness or uniqueness in a company becomes its own attraction (Teece et al., 1997).

Barney (1991) states that dynamic capabilities are processes that are embedded in the company meaning that these values are already in the company in the form of internal competence (Khaliq \& Saeed, 2015). According to Peteraf (1993) to measure dynamic capabilities is to measure capabilities or capabilities that are influenced by 
dynamic market mechanisms and their evolution (Alves et al., 2017).

Dynamic capabilities are processes of companies or organizations that use specific resources to match existing market changes with the aim of adjusting to dynamic changes that occur in the market, dynamic capabilities are also a configuration of resources that are in line with product life cycle namely developed markets, impacting, divides, develops and eventually dies/disappears, according to Eisenhardt and Martin, 2000 (Khaliq \& Saeed, 2015).

The same research about the effect of dynamic capabilities with innovation is that sustainable innovation strategies within companies can significantly improve company performance (Cabral, 2010). Chang et.al, (2012); C. L. Wang \& Ahmed (2007); Breznik \& Hisrich (2014); Strønen et al., (2017); Storer \& Hyland (2009). From the opinion above it is clear that the influence of dynamic capabilities on innovation is very significant and can improve SME performance.

3.1. Research Hypothesis

The research hypothesis is:
H1:There is a positive relationship between dynamic capabilities and SME performance

$\mathrm{H} 2$ :There is a positive relationship between dynamic capabilities and innovation

$\mathrm{H} 3$ :There is a positive relationship between innovation and SME performance

$\mathrm{H} 4$ :There is a positive relationship between dynamic capabilities and SME performance through innovation as mediation

\section{METHODOLOGY}

The sampling method used is purposive random sampling, is taking samples based on criteria determined by the pitch of the researcher. Sample criteria used are respondents who have been operating at least 5 years of business in food and beverage as many as 350 respondents. In this study an analysis tool used is structural equation modeling (SEM) version 24.

\section{RESULTS AND DISCUSSIONS}

A. Validity and Reliability

The results of the validity and reliability test of the research variables are as follows in Table 1 and Table 2

TABLE 1. THE RESULTS OF THE VALIDITY OF THE RESEARCH VARIABLE TEST

\begin{tabular}{|l|c|c|c|c|}
\hline \multicolumn{1}{|c}{ Variable } & $\begin{array}{c}\text { Coefficient } \\
\text { Correlation }\end{array}$ & Significance & Cut Of Value & Result \\
\hline Dynamic Capabilities & 0.832 & 0.000 & 0.05 & Valid \\
\hline Innovation & 0.807 & 0.000 & 0.05 & Valid \\
\hline SMEs Performance & 0,821 & 0.000 & 0.05 & Valid \\
\hline
\end{tabular}

Source : Primary data processed, 2019

TABLE 2 RESEARCH VARIABLE TEST RELIABILITY RESULTS

\begin{tabular}{|l|l|l|}
\hline \multicolumn{1}{|c|}{ Variable } & Cronbach's alpha & Result \\
\hline Dynamic Capabilities & 0,817 & Reliabel \\
\hline Innovation & 0,832 & Reliabel \\
\hline SMEs Performance & 0,821 & Reliabel \\
\hline
\end{tabular}

Source : Primary data processed, 2019

\section{B. Analysis SEM}

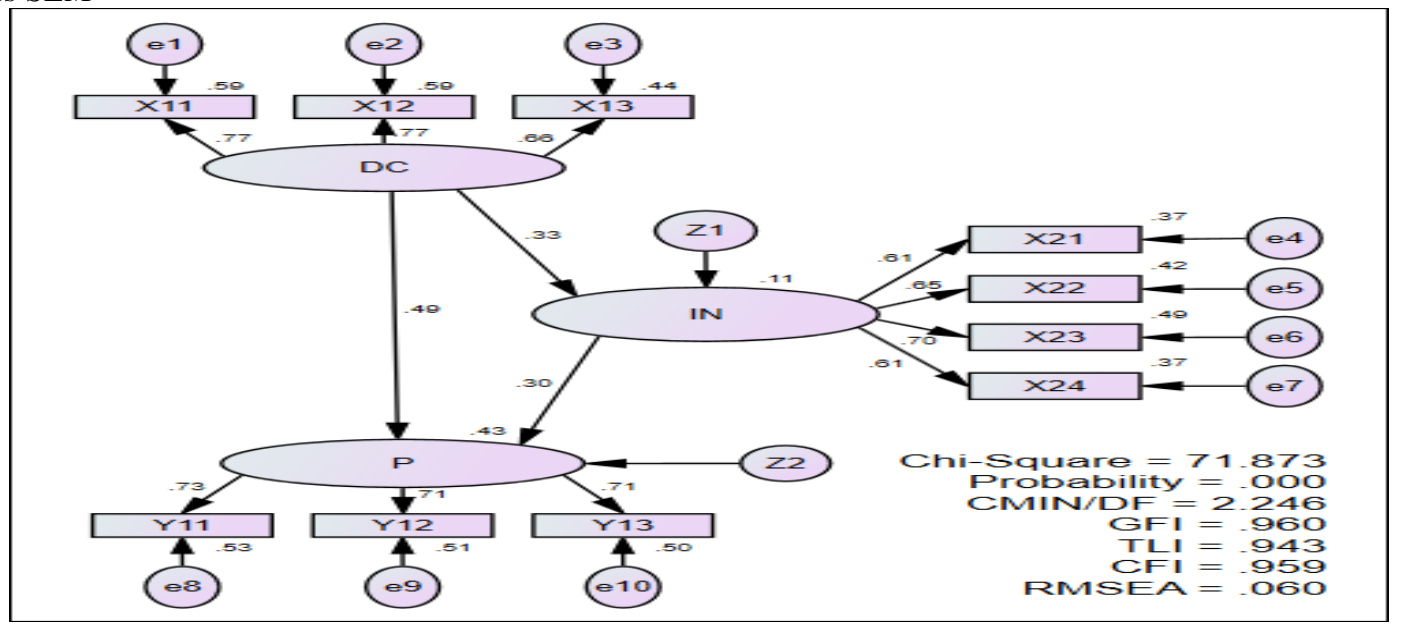

Figure 1. Result SEM 
Based on the results the analysis it is known that the analyzed model is a recursive model with a sample size of 350. Chi-Square value $=71,873$ with $\mathrm{df}=32$ and probability 0,000 . The Chi-Square results show that the null hypothesis which states the model is the same as empirical data is accepted which means the model is fit.

\section{Hypothesis Testing}

Testing of the four hypotheses proposed in this study was carried out by analyzing the value of the Critical Ratio (CR) and the probability of a causal relationship.

TABLE 3. HYPOTHESIS TESTING

\begin{tabular}{|c|c|c|c|c|c|c|c|}
\hline \multicolumn{3}{|c|}{ Variable } & Estimate & S.E. & C.R. & P & Label \\
\hline IN & $<---$ & DC & .274 & .065 & 4.212 & $* * *$ & par_7 \\
\hline P & $<--$ & DC & .547 & .085 & 6.461 & $* * *$ & par_8 \\
\hline P & $<---$ & IN & .405 & .103 & 3.941 & $* * *$ & par_10 \\
\hline
\end{tabular}

Source : Primary data processed, 2019

Based on table 5.3 presented, hypothesis testing can be explained as follows:

1) Hypothesis Testing 1

H1 : The effect of dynamic capabilities has a positive and significant effect on SMEs performance

The estimated parameter for testing the effect of dynamic capabilities on the performance of SMEs shows a CR value of 6.461 with a probability of 0,000 . Because the probability value $<0.05$, it can be concluded that the dynamic capabilities variable is proven to be positively and significantly influential on the performance of SMEs. The results of the research prove that hypothesis 1 is tested.

2) Hypothesis Testing 2

$\mathrm{H} 2$ : The effect of dynamic capabilities has a positive and significant effect on innovation.

The estimated parameter for testing the effect of dynamic capabilities on innovation shows a CR value of of 4.212 with a probability of 0.000 . Because the probability value $<0,05$, it can be concluded that the dynamic capabilities variable is proven to be positively and significantly influence SMEs performance. The results of the study prove that hypothesis 2 is tested.

3) Hypothesis Testing 3

H3 : The effect of innovation has a positive and significant effect on SMEs performance.

The estimated parameter for testing the effect of innovation on SMEs performance shows a CR value of 3.941 with a probability of 0.000 . Because the probability value $<0,05$, it can be concluded that the innovation variable is proven to have a positive and significant effect on SMEs performance. The results of the research prove that hypothesis 3 is tested.

4) Hypothesis Testing 4

$\mathrm{H} 4$ : The effect of dynamic capabilities has a positive and significant effect on SMEs performance through innovation.

The estimated parameter for testing the effect of dynamic capabilities on the performance of SMEs mediated by innovation shows a CR value of 6.461 and 3.941 with a probability of 0,000 . Therefore the probability value $<0,05$, it can be concluded thet the provrn innovation variable mediates between dynamic capabilities variables on SMEs performance. The results of the research prove that hypothesis 4 is tested.

\section{CONCLUSIONS}

From the statistical analysis results, correlation with the hypotheses, we can see the results are in table 3. Dynamic capabilities the main variables has a major influence to building the innovation and help to increasing the SMEs performance in especialy in the food and baverages industries in Indonesia. This inline with study (Cabral, 2010); (Hult, Hurley, \& Knight, 2004)); ( Strønen et al., 2017); (Juárez, De Lema, \& Guzmán, 2016); (Teece, 2014) (Muhammad et al., 2011); (Basuki et al., 2015).

Innovation factors also have an influence on improved SMEs performance. But having a smaller factors compared with dynamic capabilities. With this research we will provides some several contributions to management research and practice. The main contribution of this research to the theory:

- Provide evidence that the having of the dynamic capabilities and innovation are necessary for achieving superior SMEs performance.

- Direct correlation the dynamic capabilities have a greater influence comparing the other variables but indirect correlation innovation has greater impact to the SMEs performance.

- Provide the dynamic capabilities, innovation and SMEs performance to be used in the future research such as to the others industries sectors.

- Finally a survey study was limited only in the food and bevereges industries, so if we will capture to the industrial sectors, the areas of survey to cover all the related industries.

\section{ACHNOWLEDGEMENTS}

This article is an original work and it was not published in any other review and thank you very much to Prof. Dedi Purwana and Agung Dharmawan Buchdali Ph.D. 


\section{REFERENCES}

(1) Ackdilli Gaye and Yasar Ayhan Dogan. 2013 Dynamic Capabilities and Entrepreneurial Orientation in the New Product Development. International Journal of Bussiness and Social Science, 4 (11), 144-150.

(2) Alegre, J., Fernández-mesa, A., \& Strange, R. 2005 Entrepreneurial orientation, innovation capabilities and export performance. Journal of International Entre, 3, 223-243

(3) Alves, A. C., Barbieux, D., Reichert, F. M., Tello-Gamarra, J., \& Zawislak, P. A. 2017 Innovation and Dynamic Capabilities of the Firm: Defining an Assessment Model. Revista de Administração de Empresas, 57 (3), 232-244

(4) Basuki, Y. T., Arief, M., \& Propheto, A. 2015 The role of leadership, dynamic capabilities, and organization culture, in company performance of manufacturing industries in Indonesia (Study in food and beverages industries). Advanced Science Letters, 21 (5), 1141-1145

(5) Breznik, L., \& Hisrich, R. D. 2014. Dynamic capabilities vs . innovation capability: are they related?, (August). https://doi.org/10.1108/

(6) Cabral, J. de O. 2010 Firms'dynamic capabilities, innovative types and sustainability: A theoretical framework. XVI International Conference on Industrial Engineering and Operations Management, 1-13. 476.

(7) Carvalho, E. G., \& Sugano, J. Y. 2017 Entrepreneurial orientation and open innovation in brazilian startups: a multicase study. Interações (Campo Grande), 17 (3), 448-462

(8) Cyfert, S., \& Krzakiewicz, K. 2016 The role of opportunitysensing and learning processes in shaping dynamic capabilities in, 20 (1), 277-291.

(9) Easterby-Smith, M., \& Prieto, I. M. 2008 Dynamic capabilities and knowledge management: An integrative role for learning? British Journal of Management, 19 (3), 235-249.

(10) Fernández-Mesa, A., \& Alegre-Vidal, J. 2013 Linking Entrepreneurial Orientation and Export Intensity: How Organizational Learning Capability and Innovation Performance affect this relationship? 2013 EU-SPRI Forum Conference.

(11) Helfert, E. A 2000 Financial Analysis Tools and Techniques.

(12) Hult, G. T. M., Hurley, R. F., \& Knight, G. A. 2004 Innovativeness: Its antecedents and impact on business performance. Industrial Marketing Management, 33 (5), 429438.

(13) Hurley, R. 2012 Self Management and Leadership World class leaders and managers of others manage themselves first (203).

(14) KU.Rehmain Cheema, Z. S. 2015. Impact of Dynamic Capabilities on Firm Performance: Moderating Role of Organizational Competencies Impact of Dynamic Capabilities on Firm Performance (December). https://doi.org/10.30537

(15) Lee, T. S., \& Tsai, H. J. 2005 The effects of business operation mode on market orientation, learning orientation and innovativeness. Industrial Management and Data Systems (Vol. 105).

(16) Lin, K. 2012 Kuo-Wei Lin and 2 Kai-Ping Huang Department of International Business, College of Management, School of Management, Faculty of Business , 9 (1), 107-110.

(17) Mohammad, I. N., Massie, J. D. D., Tumewu, F. J., \& Program, M. 2019 The Effect Of Entrepreneurial Orientation And Innovation Capability Towards Firm Performance In Small And Medium Enterprises (Case Study: Grilled Restaurants in Manado ), 7(1).

(18) Muhammad, Q., Abro, M., Memon, N. A., Irfanullah, P. I. R., \& Arshdi, S. 2011 Dynamic Capabilities and Firm Performance: A Case of Two SMEs in Pakistan, 30 (3).

(19) Ozmen, O. N. T., \& Deniz Eris, E. 2012 The effect of market orientation, learning orientation and innovativeness on firm performance: A research from Turkish logistics sector. International Journal of Economic Sciences and Applied Research, 5 (1), 77-108.

(20) Pandit, Joshi, M., Gupta, R. K., \& Sahay, A. 2017 Disruptive innovation through a dynamic capabilities lens : an exploration of the auto component sector in India Disruptive innovation through a dynamic capabilities lens : an exploration of the auto component sector in India Deepak Pandit* Rajen K . Gup, (January 2018). https://doi.org/10.1504

(21) Ramón, J., Lorenzo, F., Teresa, M., Rubio, M., \& Garcés, S. A.
2018 The competitive advantage in business , capabilities and strategy. What general performance factors are found in the Spanish wine industry? Wine Economics and Policy, 7 (2), 94 108.

(22) Rehman Khaliq, U., \& Zafar Saeed. 2015 Impact of Dynamic Capabilities on Firm Performance: Moderating Role of Organizational Competencies. Sukkur IBA Journal of Management and Business, 2 (2), 18-40

(23) Robbins, S. 2005 Principles of organizational behavior. International, Prentice Hall.

(24) Rubina Jabeen, Jamal Mohammed Esmail Alekam, Khaldoun Ahmed Mohammed Aldaoud, Nik Kamariah Nik Mat, Bila Nayef Ibrahim Zureigat, Alharbi Khalid Nahi, Alaa Muhammad Fadel al Junaidi, H. 2013 Antecedents of Firm' S Performance Empirical Evidence from Yemeni SME' S. American Journal of Economics, 3 (1), 18-22.

(25) Serna, de lem.2012 Knowledge management and business performance Does innovation matter Cogent Business \& Management_ Vol 4, No 1.

(26) Strønen, F., Hoholm, T., Kværner, K., \& Støme, L. N.2017 Dynamic capabilities and innovation capabilities: The case of the 'Innovation Clinic.' Journal of Entrepreneurship, Management and Innovation, 13 (1), 89-116.

(27) Suliyanto, \& Rahab. 2012 The role of market orientation and learning orientation in improving innovativeness and performance of small and medium enterprises. Asian Social Science, 8 (1), 134-145.

(28) Teece, D. J. 2014 A dynamic capabilities-based entrepreneurial theory of the multinational enterprise, $8-37$

(29) Teece, D. J. 2018 Business models and dynamic capabilities * Long Range Planning, 51 (1), 40-49.

(30) Teece, D. J., Pisano, G., \& Shuen, A. 1997 Dynamic capabilities and strategic management. Strategic Management Journal.

(31) Valdez-Juárez, L. E., De Lema, D. G. P., \& Maldonado-Guzmán, G. 2016 Management of knowledge, innovation and performance in SMEs. Interdisciplinary Journal of Information, Knowledge, and Management, 11, 141-176.

(32) Vargas-Hernández, J. G., Research, M. B. A. ;, \& MuratallaBautista, G. 2017 Dynamic Capabilities Analysis In Strategic Management Of Learning And Knowledge Management Of Learning Absorption. Race, 16 (1), 2017

(33) (https://ekonomi.kompas.com/read/2018/10/31/204100326/srimulyani--umkm-serap-96-persen-tenaga-kerja) 